\title{
Metastatic melanoma in breast imaging: A case report
}

\author{
Huws A.M * Dias J, Moalla A, Semkin L, Holt S.D.H \\ Breast Unit Hywel Dda NHS University Trust, Llanelli, Carmarthenshire, Wales, UK
}

Received: October 28, 2015

Accepted: November 19, $2015 \quad$ Online Published: November 24, 2015

DOI: $10.5430 /$ crcp.v3n1p23

URL: http://dx.doi.org/10.5430/crcp.v3n1p23

\begin{abstract}
Metastases to the breast are well documented with cutaneous melanoma, pulmonary and gynaecological tumours accounting for the majority. It is important to consider metastatic tumour in the differential diagnosis when presented with unusual clinical or radiological findings. This study illustrates multi-system clinical findings and highlights the diversity of imaging findings in metastases to the breast. It demonstrates how metastatic melanoma treatment has been revolutionised by the introduction of targeted therapies and immunotherapy with a dramatic response to treatment with a B-raf proto-oncogene (BRAF) and Mitogen-activated protein kinase (MEK) inhibitors combination.
\end{abstract}

Key Words: Metastases to breast, Malignant melanoma, B-raf proto-oncogene and Mitogen-activated protein kinase inhibitors

\section{INTRODUCTION}

Breast imaging and routine screening has improved the detection and assessment of breast cancer. Although metastases to the breast are rare, accounting for less than $2 \%$ of all breast malignancies, ${ }^{[1,2]}$ it is important to identify these such that unnecessary treatment and procedures are avoided. Retrospective reviews show that the majority of patients with breast metastases have a known history of malignancy, with malignant melanoma, lung and gynaecological tumours accounting for the majority. ${ }^{[3,4]}$

Imaging findings of breast metastases from non-mammary malignancies are variable. Previous studies have suggested that appearances may be related to the route of spread, either haematogenous or lymphatic, ${ }^{[5]}$ but most will be well defined on ultrasound and mammography examination. Typically, there is no posterior acoustic shadowing on sonography ${ }^{[6]}$ and the lesions are rarely associated with microcalcifications on mammography. ${ }^{[5-7]}$

Our case illustrates the imaging appearances of breast metas- tases from a primary malignant melanoma diagnosed 28 years previously, and demonstrates how the development of new treatments has improved the outcome of patients with widespread metastatic melanoma.

\section{CASE PRESEntation}

A 63-year-old Caucasian patient was referred with a four week history of a firm $2 \mathrm{~cm}$ mass in the flexor surface of the upper arm adjacent to the axilla. She had no breast symptoms and was otherwise asymptomatic. She had a superficial spreading melanoma on her left calf treated in 1989 by excision and grafting. She was noted to be on methotrexate for rheumatoid arthritis.

Examination confirmed the mass in the left upper arm which measured $2.45 \mathrm{~cm} \times 1.42 \mathrm{~cm}$ on sonography. The lesion was heterogeneously hypoechoic with irregular margins, imaging findings were considered consistent with the presence of a sarcoma. Mammography and whole breast ultrasound demonstrated well defined lesions in both breasts which were

\footnotetext{
*Correspondence: Huws A.M; Email: Anita.Huws@wales.nhs.uk; Address: Breast Unit Hywel Dda NHS University Trust, Llanelli, Carmarthenshire, Wales, SA14 8QF, UK.
}

Published by Sciedu Press 
indeterminate in appearance. Ultrasound guided $14 \mathrm{G}$ core biopsies were performed of these lesions, excluding the le- sion on the flexor surface of the left upper arm in light of the clinical suspicion of sarcoma (see Figures 1-4).
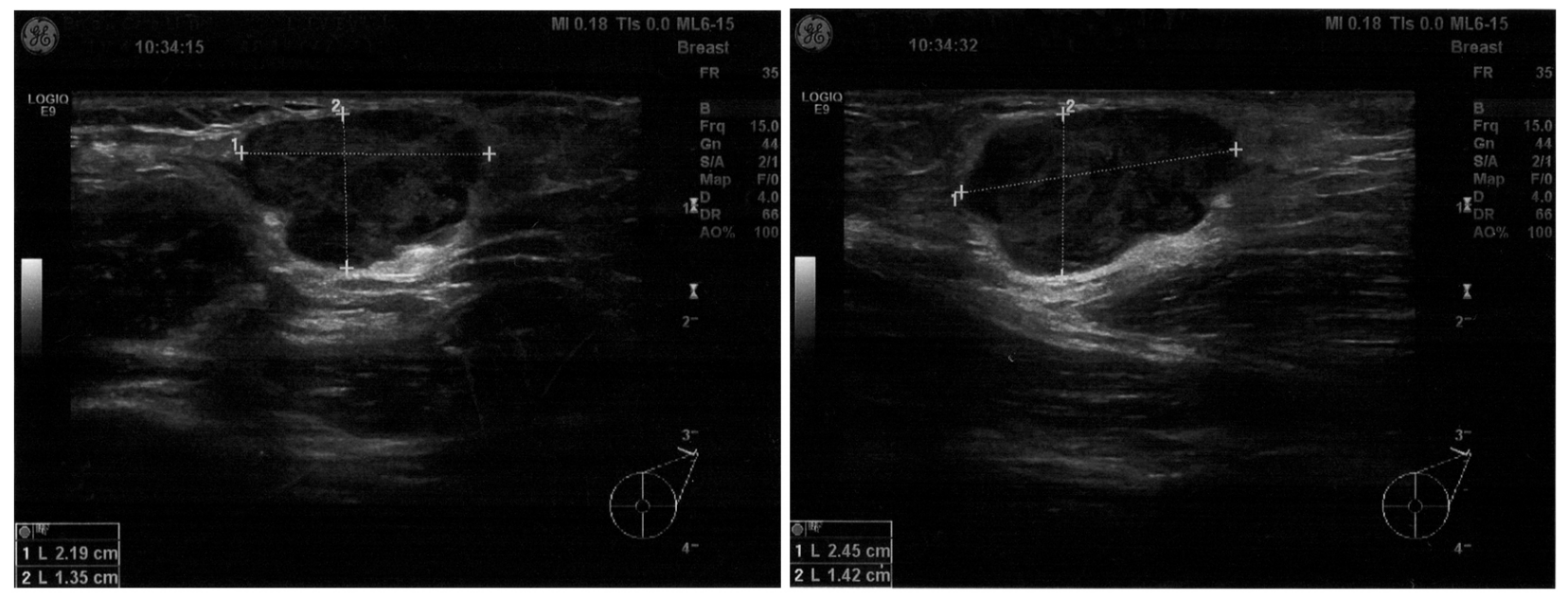

Figure 1. Ultrasound images of the lesion lateral to the left axilla demonstrating a superficial, irregular, fairly well-defined, heterogeneously hypoechoic lesion measuring $2.45 \mathrm{~cm} \times 2.18 \mathrm{~cm} \times 1.42 \mathrm{~cm}$. The lesion had mixed vascularity on doppler.
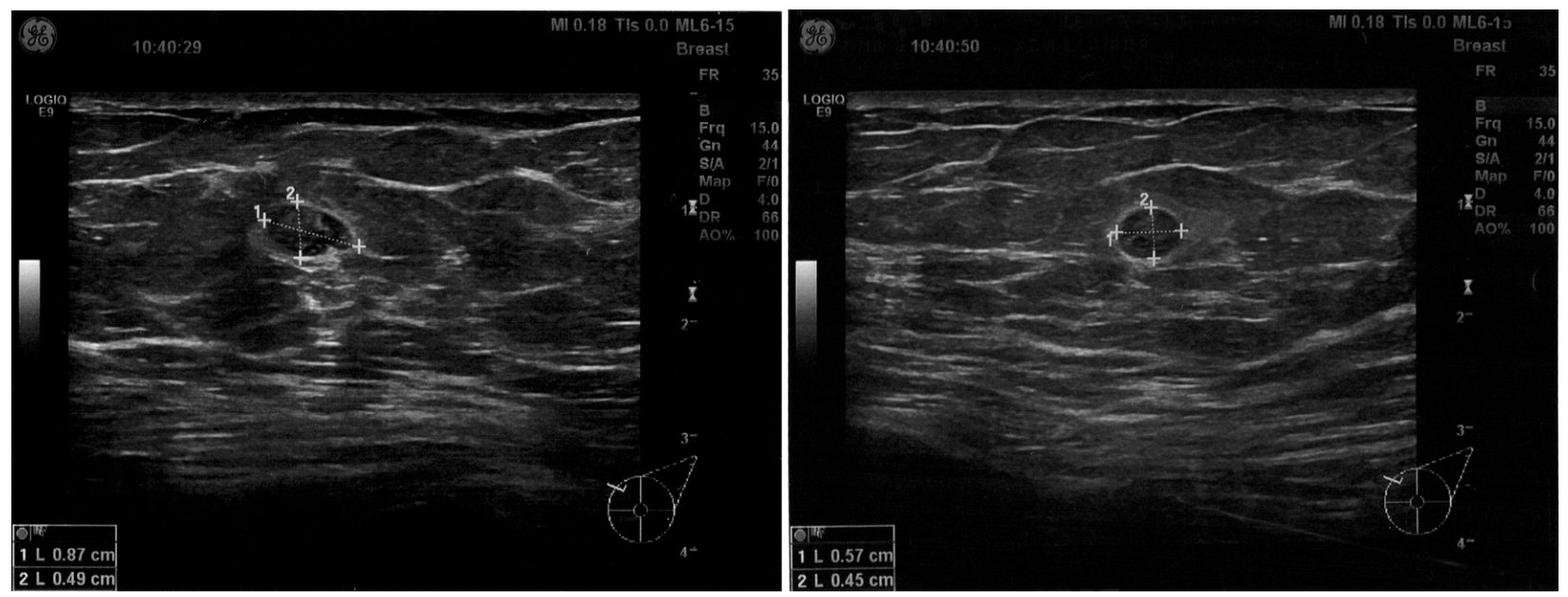

Figure 2. Ultrasound images of left breast lesion in the upper, inner quadrant demonstrating horizontally orientated, heterogeneously hypoechoic lesions with no posterior effect, causing no disruption to the surrounding breast parenchyma

During the assessment she was noted to have significant left proptosis and, on questioning, admitted to diplopia and tenderness in the eye. Ophthalmological assessment confirmed no field loss or papilloedema. An urgent Computed Tomography $(\mathrm{CT})$ of the head demonstrated a $19 \mathrm{~mm}$ soft tissue mass in the lateral aspect of the left orbit displacing adjacent structures, but with no bony erosion (see Figure 5).

CT scan thorax, abdomen and pelvis showed widespread metastases within the thorax and abdomen, with a $12 \mathrm{~mm}$ mass in the lateral aspect of the right breast, with an additional lesion in the inner quadrant of the left breast. Multiple metastatic deposits in the pleura, lung, and several subcutaneous sites with a liver metastasis, with further distribution in the intra-abdominal fat. Abnormal lymph nodes seen in the mediastinum, left groin and iliac fossa regions (see Figures 6-8).

\section{Histology section breast melanoma}

Core biopsy of the lesion revealed infiltration of the breast tissue by sheets of cells showing epithelioid morphology (A), marked cellular atypia and high mitotic activity (B). The immunophenotype of this tumour was confusing. The tumour cells were strongly S-100 protein positive (C). The lesional cells show negative staining for Pan epithelial marker (AE1/3) and leukocyte common antigen (CD45), and were also negative for ER. However, surprisingly, the expression 
of other melanoma markers, such as Melan-A (D) and HMB45 was lost in this metastatic tumour (see Figure 9).

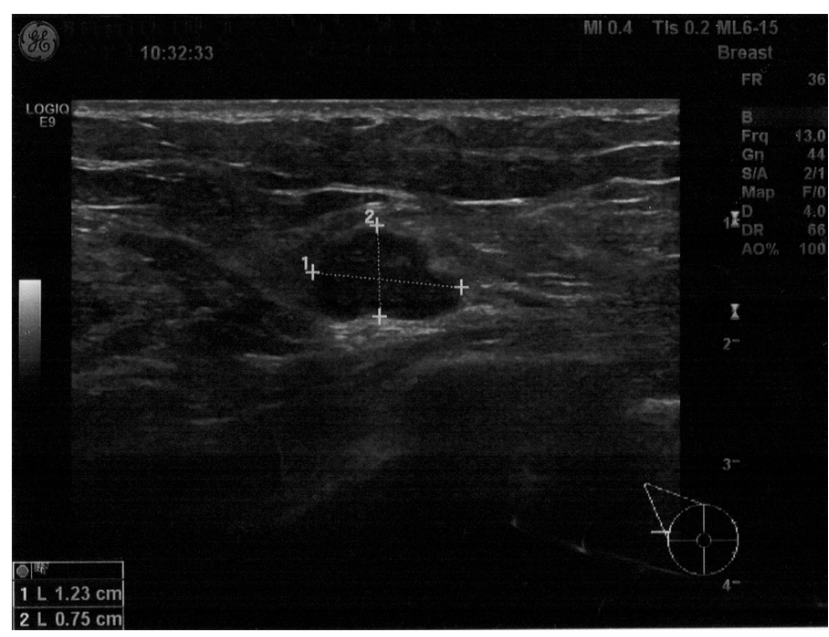

Figure 3. Ultrasound images of the right breast lesion in the lateral aspect of the breast demonstrating a well defined fairly uniformly hypoechoic lesion with no posterior effect measuring $1.21 \mathrm{~cm} \times 0.75 \mathrm{~cm}$

Genetic testing confirmed a BRAF mutation.

Dermatological review did not reveal any pigmented skin lesions suggestive of a second primary melanoma. The patient was seen by the oncology team and commenced on the B-raf proto-oncogene (BRAF) inhibitor darafenib and the Mitogenactivated protein kinase (MEK) inhibitor trametinib.

Following a month of treatment, CT Head, Thorax and Abdomen, and pelvis confirmed almost complete resolution of the widespread metastases although the lesion in the liver remained. She is currently asymptomatic 8 months since diagnosis having had complete resolution of the proptosis and diplopia after 1 month of treatment. She is experiencing no debilitating side-effects from the treatment and has an excellent performance status. Serial CT scans show no evidence of disease. Images taken 5 months later demonstrate the treatment response (see Figures 10-13).

\section{Discussion}

Malignant melanoma is the most aggressive of all skin cancers with an increasing incidence in the UK. It is the most common solid malignancy to metastasise to breast ${ }^{[3,4]}$ and, although rare, most patients have a prior history of malignant melanoma ${ }^{[3]}$ with the majority of patients being female and in their 4th-6th decade. ${ }^{[1,2,4]}$ The median time from diagnosis of the primary melanoma and metastasis was 62 months in two series (range 13-180 months). ${ }^{[3,4,8]}$ A recent study from a single institution reported a series of 18 patients with metastatic disease to the breast and a third of these were from

Published by Sciedu Press malignant melanoma; one patient presented 23 years after the primary diagnosis, which is still less than our case which was originally treated over 28 years previously. ${ }^{[9]}$ Most patients present with disseminated disease, ${ }^{[2,3]}$ although one series shows that about half $(46.1 \%)$ of the patients with widespread disease show only a solitary metastasis in the breast. ${ }^{[4]}$ Most of these patients were detected through routine breast screening. Survival rates are poor being less than a year in most series when treated with previously available therapies. ${ }^{[2-4]}$

The majority of the reports in the literature are small historical series or case reports, which limits the application of findings to current practice.

\subsection{Imaging findings}

\subsubsection{Sonography}

Imaging findings of metastatic breast lesions are heterogeneous, and can mimic benign lesions or appear very similar to primary breast cancer. ${ }^{[6,10,11]}$ Clinical suspicion should be raised in a patient with a history of a prior malignancy. Although the imaging appearance can be variable most papers agree that there is usually no posterior effect, and vascularity is variable on Doppler assessment. ${ }^{[6,11-13]}$ Our case demonstrated sonographic appearances in the breast of well defined, hypoechoic lesions with normal Doppler flow but no posterior effect. However the lesion on the left upper arm looked suspicious and had an abnormal Doppler flow pattern.

\subsubsection{Mammography}

Mammographic appearances of metastatic deposits are usually seen as fairly superficial lesions with circumscribed margins, typically in the upper outer quadrant of the breast, and rarely associated with calcifications. ${ }^{[2,3,6]}$ Although uncommon, metastatic lesions in the breast can be associated with calcifications most notably from ovary. ${ }^{[14]}$ Lymph node involvement was found in approximately $25 \%$ to $50 \%$ of cases, ${ }^{[2,6,13]}$ although axillary nodal involvement was more frequently noted in patients with malignant lymphoma. Mammographic findings in this case demonstrated well defined lesions that looked probably benign (M3) with no associated microcalcifications and were in the upper inner quadrant and lateral aspect of both breasts.

\subsection{Pathology}

A 10 year review of patients with non-mammary metastases to the breast found that failure to provide the pathologist with the past history of malignancy resulted in a delay in recognising the lesion as metastatic, especially as many of the tumours in some series had similar morphological appearance and immunohistochemistry to primary breast cancer ${ }^{[15]}$ Relevant to our case, the histological appearance of metastatic 
melanoma may be untypical as the lesion may not produce melanin. ${ }^{[16,17]} \mathrm{S} 100$ is expressed in $95 \%$ of melanomas but is not specific as it is present in $50 \%$ of breast cancers; ${ }^{[15]}$ for this reason, the IHC panel normally includes HMB45

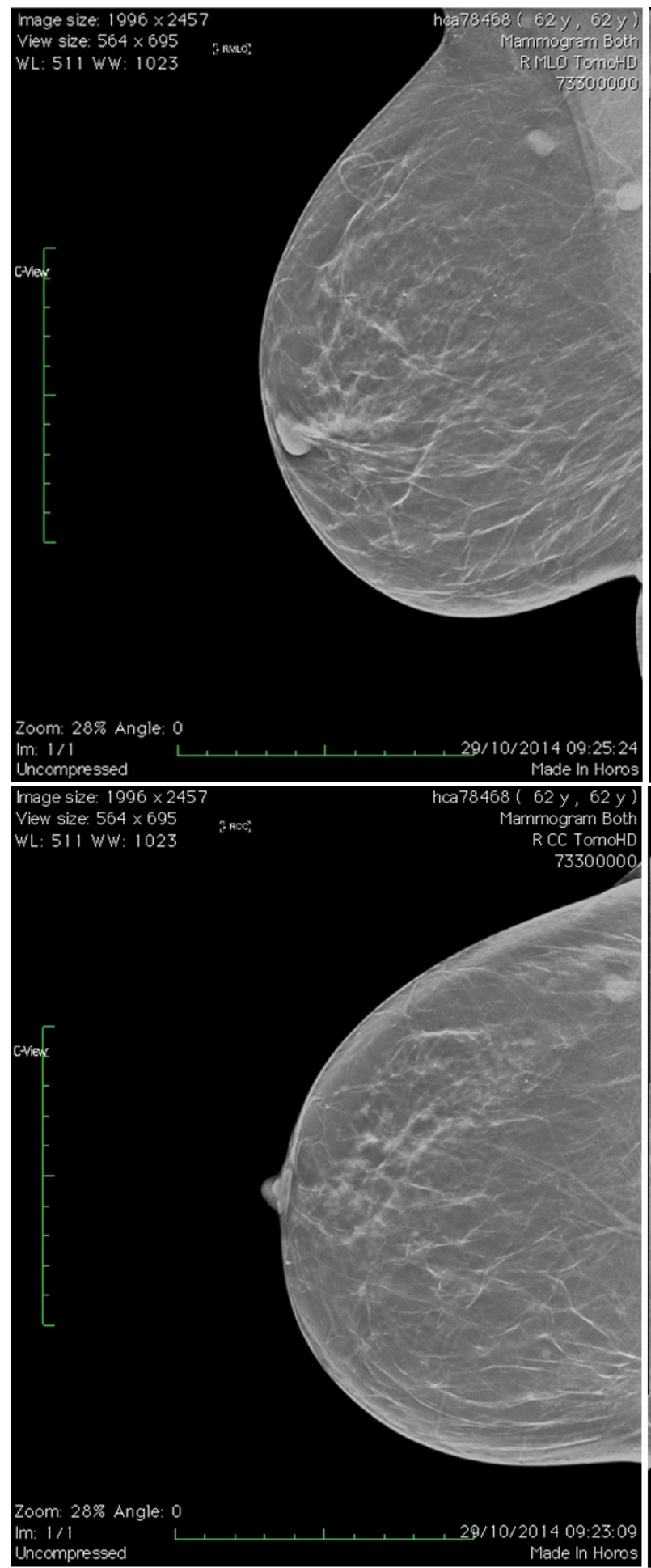

and melan- $\mathrm{A}^{[15]}$ to confirm the diagnosis. Other markers for melanoma include microphthalmia transcription factor and tyrosinase are more specific than S100, but may be less sensitive, being present in only about $70 \%$ of melanomas. ${ }^{[15,18]}$

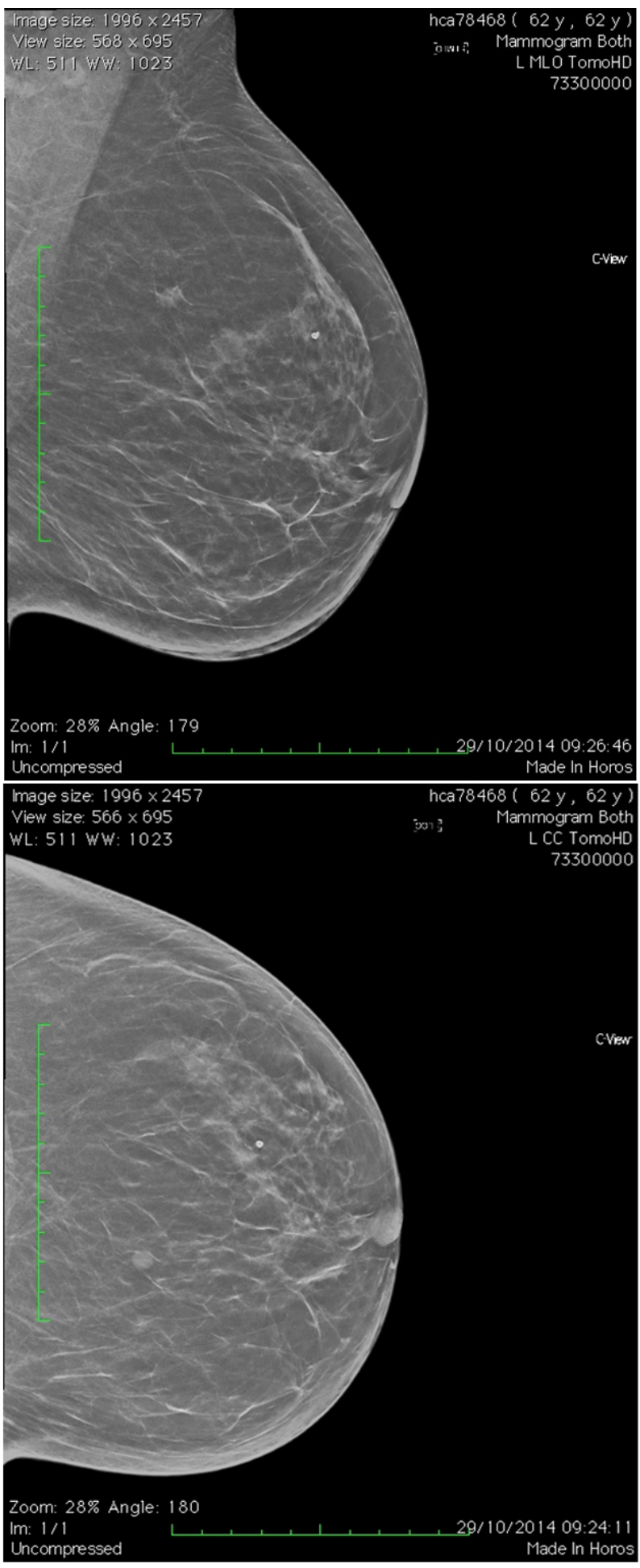

Figure 4. Digital Breast Tomosynthesis Images of breast lesions demonstrating well defined lesions in both breasts 


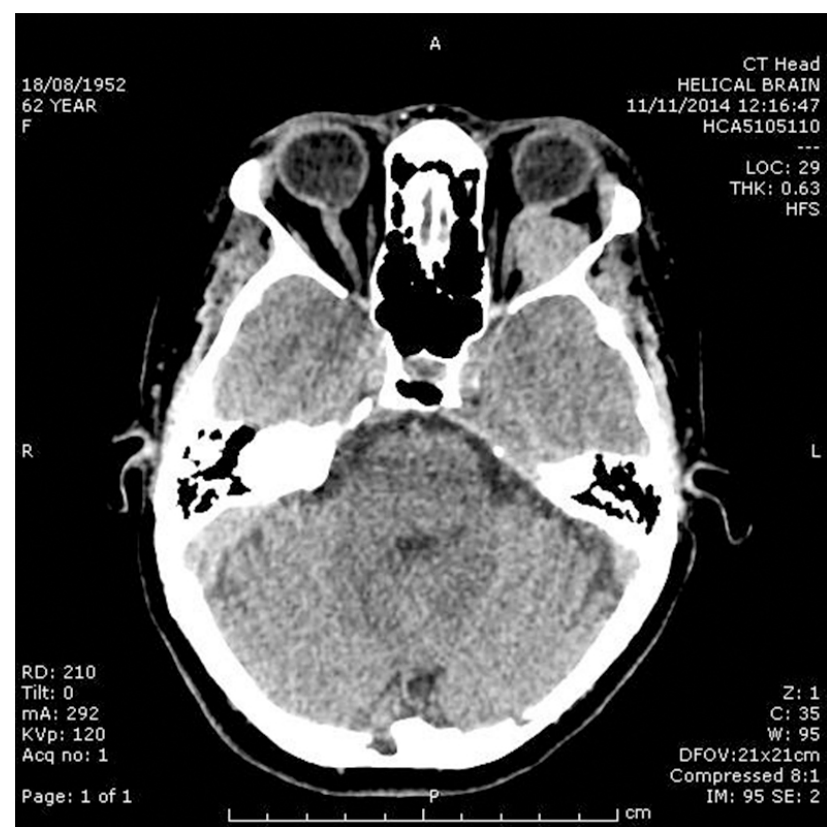

Figure 5. CT Head at diagnosis demonstrating a $19 \mathrm{~mm}$ soft-tissue mass in the lateral aspect of the left orbit displacing adjacent structures, but with no bony erosion

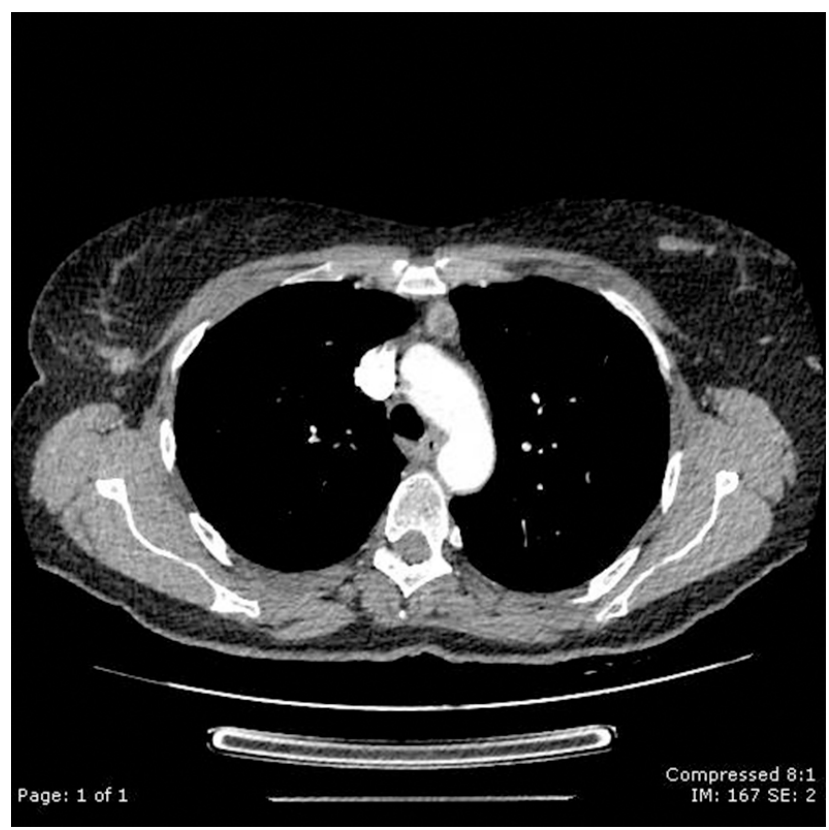

Figure 6. CT scan demonstrating mediastinal lymph node

\subsection{Therapeutic options}

As molecular profiling of tumours increases so do the therapeutic options. This case was found to have a BRAF mutation and she was commenced on the BRAF inhibitor dabrafenib and MEK inhibitor trametinib.

Published by Sciedu Press

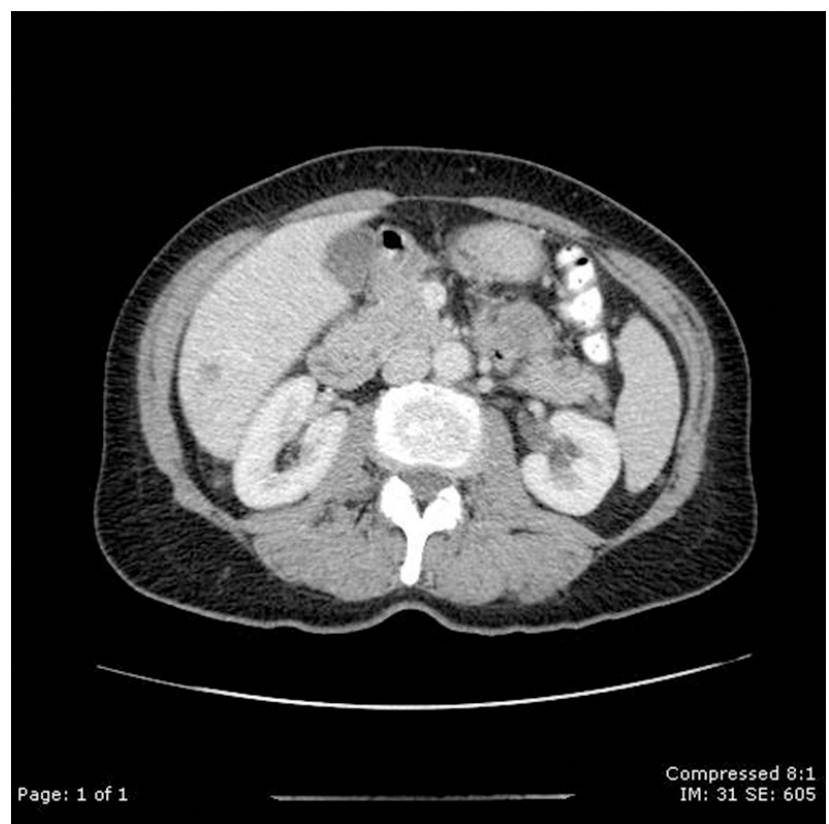

Figure 7. Liver metastasis

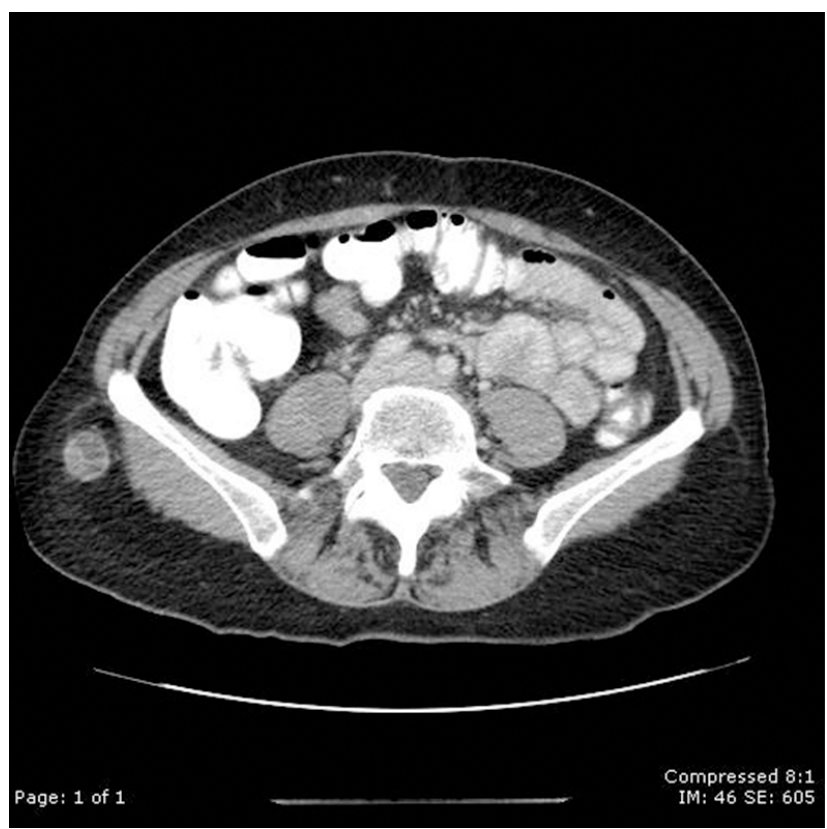

Figure 8. Soft tissue metastasis

The combination has been shown to improve the response rate and progression-free survival in melanoma and reduces the skin toxicities seen with dabrafenib alone. ${ }^{[19]}$ The patient continues with an excellent performance status, and no significant side-effects. Serial CT Scans demonstrate excellent response to treatment with no radiological evidence of residual disease. There is emerging evidence that patients with metastatic melanoma may eventually become resistant to treatment even with the BRAF and MEK inhibitor combination, and some studies are looking at more targeted therapy. ${ }^{[20]}$ 


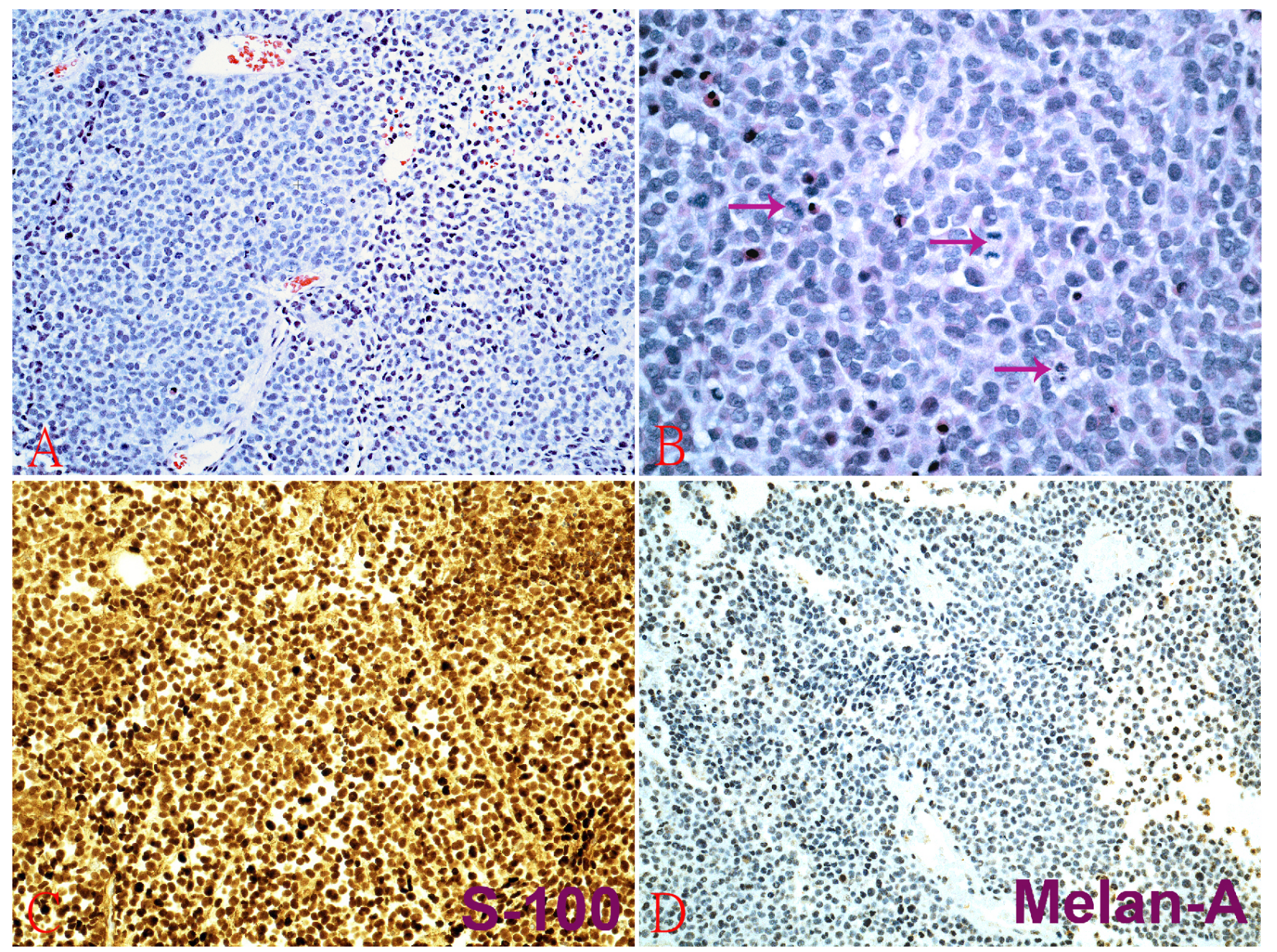

Figure 9. Histologic images. A: Infiltration by Melanoma cells; B: Cellular atypia and plenty of mitoses (arrows); C: Positive expression of S-100 protein marker; D: Negative expression of Melan-A marker.

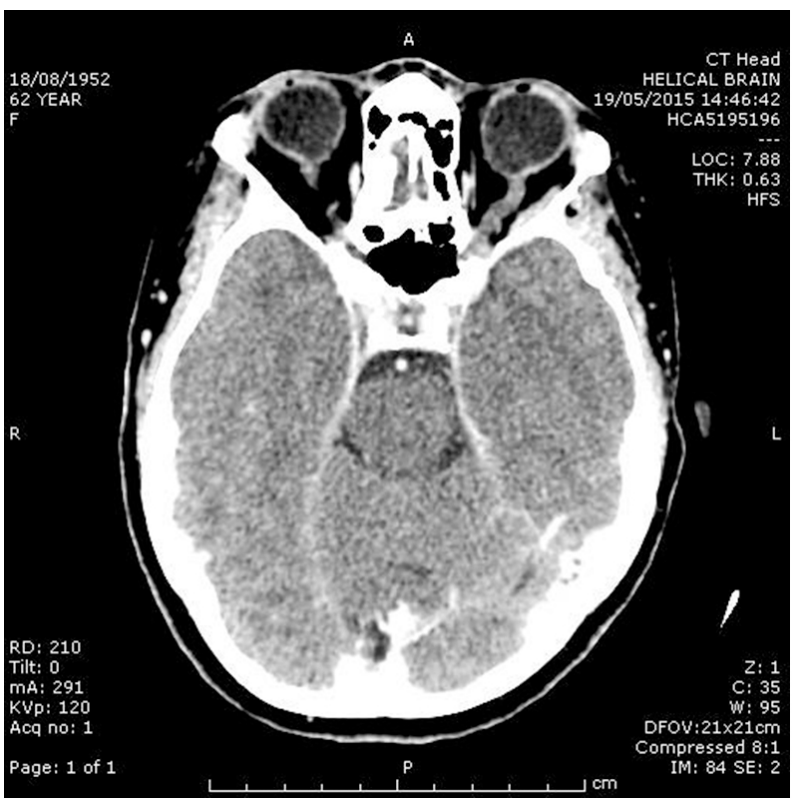

Figure 10. CT Scan Head demonstrating good response to treatment with no evidence of the soft-tissue mass in the lateral aspect of the left orbit

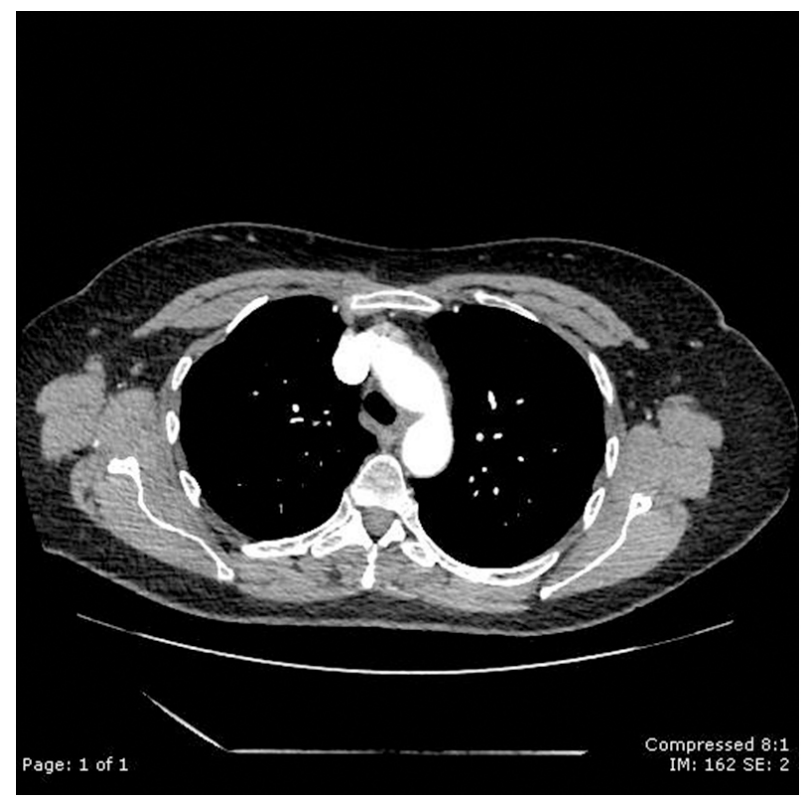

Figure 11. Mediastinal lymph node post treatment 


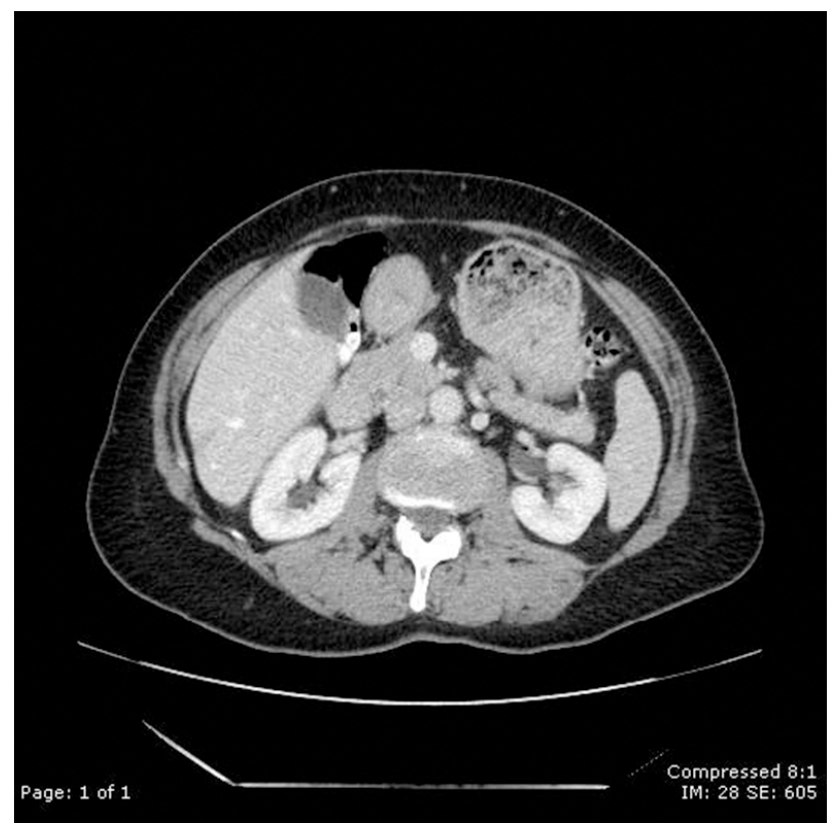

Figure 12. CT Images thorax and abdomen at 5/12 post-treatment demonstrating good response to treatment. The solitary lesion in the liver is no longer visible.

\section{Conclusion}

This case illustrates how molecular targeted therapy is improving the management of metastatic melanoma. The combination of dabrafenib and trametinib has been approved by European authorities, and more recently approved by the US FDA in January 2014. Data from the phase 3 studies COMBI- $\mathrm{d}^{[21]}$ and COMBI-v $\mathrm{v}^{[22]}$ have both demonstrated a survival benefit. The COMBI-d study showed a survival advantage of the combination compared with dabrafenib alone of 6 months, and the COMBI-v study compared the combination with vemurafenib (a BRAF inhibitor) with $72 \%$ of patients alive on the combination compared with $65 \%$ on vemurafenib at a year.

The use of targeted therapies and the development of checkpoint inhibitors to modulate the immune response to im- munogenically active tumours such as melanoma is a rapidly developing and a very promising area in oncology.

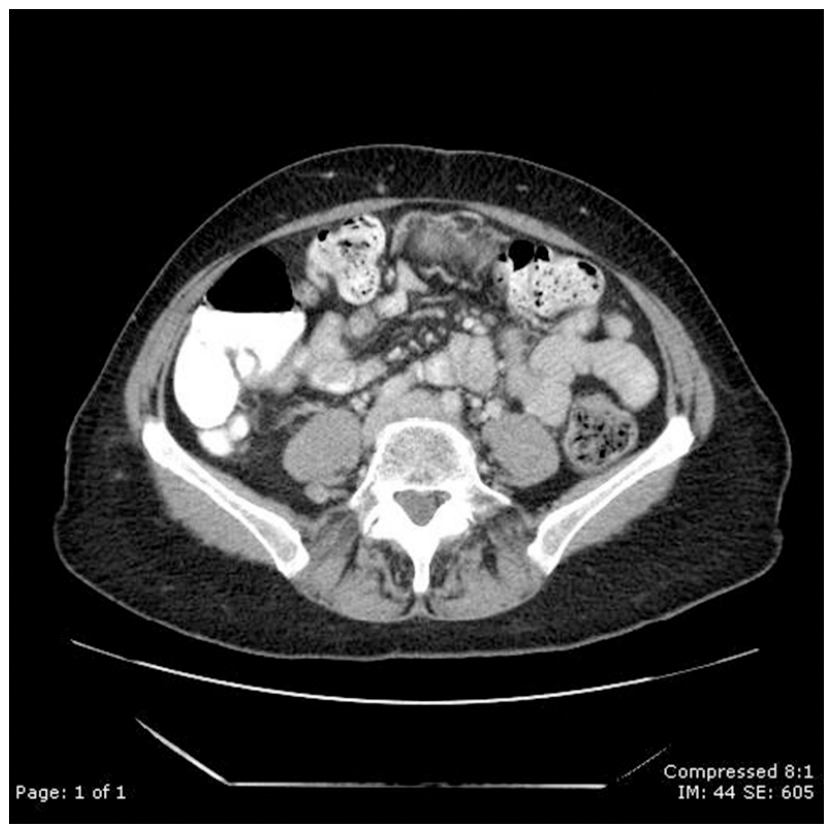

Figure 13. Soft tissue metastases no longer visible on $5 / 12$ post treatment CT scan

\section{Consent}

Written informed consent was obtained from the patient for publication of the case report and the images. A copy of the written consent is available for review by the Editor-in-Chief of this journal.

\section{Authors Details}

All authors have made substantial contributions to the conception and design of the case report, acquisition of data and images, drafting and revision of the article. All authors have approved the final article.

\section{CONFlicts OF InTEREST Disclosure}

The author(s) declare that there are no competing interests.

\section{REFERENCES}

[1] Georgiannos SN, Chin J, Goode AW, et al. Secondary neoplasm of the breast. Cancer. 2001; 92: 2259-66. http://dx.doi.org/10.1002/1097-0142(20011101)92: 9<2259: : AID-CNCR1571>3.0.CO;2-0

[2] Toombs BD, Kalisher L. Metastatic disease to the breast: clinical, pathologic and radiographic fea-tures. Am J Roentgenol. 1977; 129: 673-6. PMid: 409241. http://dx.doi.org/10.2214/ajr.129 .4 .673

[3] Ravdel L, Robinson WA, Lewis K, et al. Metastatic Melanoma in Published by Sciedu Press the Breast: A report of 27 cases. Journal Surgical Oncol. 2006; 94: 101-104. PMid: 16847918. http://dx.doi.org/10.1002/jso .20592

[4] Williams SA, Ehlers RA II, Hunt KK, et al. Metastases to the breast from nonbreast solid neoplasms: presentation and determinants of survival. Cancer. 2007; 110: 731-7. PMid: 17582626. http://dx.doi.org/10.1002/cncr. 22835

[5] Mun SH, Ko EY, Han B-K, et al. Breast metastases from extramammary malignancies: typical and atypi-cal ultrasound features. Korean J Radiol. 2014; 15(1): 20-8. PMid: 24497788. http: 
//dx.doi.org/10.3348/kjr.2014.15.1.20

[6] Yang WT, Metreweli C. Sonography of nonmammary malignancies of the breast. A Pictorial Essay. AJR. 1999; 172: 343-8. PMid 9930779. http://dx.doi.org/10.2214/ajr.172.2.9930779

[7] Welsh SJ, Corrie PG. Management of BRAF and MEK inhibitor toxicities in patients with metastatic mel-anoma. The Adv Med Oncol. 2015; 7(2): 122-36. PMid: 25755684. http://dx.doi.org/10. $1177 / 1758834014566428$

[8] Loffied A, Marsden JR. Management of melanoma metastasis to the breast: case series and review of the literature. British Journal of Dermatology. 2005; 152: 1206-10. PMid: 15948983. http: //dx.doi.org/10.1111/j.1365-2133.2005.06574.x

[9] Vaughan A, Dietz JR, Moley JF, et al. Metastatic disease to the breast: the Washington University experi-ence. World J Sur Oncol. 2007; 5: 74-82. PMid: 17615059. http://dx.doi.org/10.1186/1477-7 819-5-74

[10] Lee AHS. The histological diagnosis of metastases to the breast from extramammary malignan-cies. J Clin Pathol. 2007; 60: 1333-41. PMid: 18042689. http://dx.doi.org/10.1136/jcp. 2006.04 6078

[11] Lee SH, Park JM, Kook SH, et al. Metastatic tumors to the breast; mammographic and ultrasonon-graphic findings. J Ultrasound Med. 2000; 19: 257-62. PMid: 10759349.

[12] Jue KF, Lewin JM, et al. Unusual sonographic appearance of melanoma metastases in the breast. J Ultrasound Med. 2006; 25: 663-6. PMid: 16632791

[13] Yang WT, Metreweli C. Sonography of nonmammary malignancies of the breast. AJR. 1999; 172: 343-8. PMid: 9930779. http: //dx.doi.org/10.2214/ajr.172.2.9930779

[14] Ozsaran AA, Dikmen Y, Terek MC. Bilateral metastatic carcinoma of the breast from primary ovar-ian cancer. Arch Gynecol Obstetr. 2000; 264(3): 166-7. http://dx.doi.org/10.1007/s004040000098

[15] DeLair DF, Corben AD, et al. Non-mammary metastases to the breast and axilla: a study of 85 cases. Modern Pathology. 2013; 26: 343-9.
PMid: 23174933. http://dx.doi.org/10.1038/modpathol.2 012.191

[16] Lee AHS. The histological diagnosis of metastases to the breast from extramammary malignan-cies. J Clin Pathol. 2007; 60: 1333-41. PMid: 18042689. http://dx.doi.org/10.1136/jcp. 2006.04 6078

[17] Bacchi CE, Wludarski SC, Ambaye AB, et al. Metastatic melanoma presenting as an isolated breast tumor. Arch Pathol Lab Med. 2013; 137: 41-9. PMid: 23276173. http://dx.doi.org/10.5858/arp a. 2011-0552-0A

[18] Weinstein D, Leininger J, Hamby C, et al. Diagnostic and prognostic biomarkers in melanoma. J Clin Aesthet Dermatol. 2014; 7(6): 13-24. PMid: 25013535.

[19] Luke J, Ott PA. New developments in the treatment of metastatic melanoma-role of dabrafenib-trametinib combination therapy. Drug Healthcare and Patient Safety. 2014; 6: 77-88. PMid: 25018652. http://dx.doi.org/10.2147/DHPS.S39568

[20] Spagnolo F, Ghiorzo P, Orgiano L, et al. BRAF-mutant melanoma: treatment approaches, resistance mechanism, and diagnostic strategies. OncoTargets and Therapy. 2015; 8: 157-168. PMid: 25653539. http://dx.doi.org/10.2147/OTT.S39096

[21] Long GV, Stroyakovsky DL, Gogas H, et al. COMBI-d: A randomized double-blinded, Phase III Study comparing the combination of dabrafenib and trametinib to dabrafenib and trametinib placebo as first-line therapy in patients with unresectable or metastatic BRAFV600E/K mutation positive cutaneous melanoma. J Clin Oncol. 2014; 32: 5s (suppl; abstr 9011^).

[22] Robert C, Karaszewska B, Schachter J, et al. Two year estimate of overall survival in COMBI-v, a randomized, open-label, phase III study comparing the combination of dabrafenib and trametinib vs vemurafenib as first-line therapy in patients with unresectable or metastatic BRAF V600E/K mutation-positive cutaneous melanoma (Abstract 3301). 2015 European Cancer Congress; Presented September $28,2015$. 